\title{
Optimization of Culture Conditions in a Bioreactor for the Production of Biomass and Metabolites of the Macromycete Lentinula Edodes
}

Carolina Chegwin-Angarita ( $\sim$ cchegwina@unal.edu.co)

Universidad Nacional de Córdoba: Universidad Nacional de Cordoba https://orcid.org/0000-00023150-9972

\section{Robinson A. Bello-Forero}

Universidad Nacional de Colombia - Sede Bogotá: Universidad Nacional de Colombia

Juan C. Serrato-Bermúdez

Universidad Nacional de Colombia - Sede Bogotá: Universidad Nacional de Colombia

\section{Research Article}

Keywords: Fermentation in liquid state, macromycete, Lentinula edodes, sterols, polysaccharides

Posted Date: June 16th, 2021

DOI: https://doi.org/10.21203/rs.3.rs-610654/v1

License: (c) (i) This work is licensed under a Creative Commons Attribution 4.0 International License. Read Full License 


\title{
Optimization of culture conditions in a bioreactor for the production of biomass and
}

\section{metabolites of the macromycete Lentinula edodes}

\author{
Carolina Chegwin-Angarita $^{a^{*}}$, Robinson A. Bello-Forerob ${ }^{b}$ Juan C. Serrato-Bermúdez $^{c}$ \\ a Department of Chemistry, Universidad Nacional de Colombia, Bogotá, Colombia. \\ b,c Department of Chemical and Environmental Engineering, Universidad Nacional de Colombia, Bogotá, Colombia \\ Corresponding author: cchegwina@unal.edu.co \\ ORCID: ${ }^{b} 0000-0002-3150-9972$ \\ ${ }^{b} 0000-0002-9896-6422$ \\ c0000-0002-9092-0585
}

\section{Abstract}

Lentinula edodes is an edible mushroom known for its medicinal properties attributed to different secondary metabolites. In this article, the effect of glucose concentration, aeration and agitation on the production of biomass and intrametabolites in submerged fermentation was evaluated. By means of a Box-Behnken design, these variables were optimized to obtain a multifunctional biomass. It was determined that both glucose concentration and agitation had a significant effect on the response variables (biomass, sterols and polysaccharides). Under the evaluated conditions, the values of the variables that optimize biomass production were 1.2 vvm, 60 rpm and $21.97 \mathrm{~g} / \mathrm{L}$ of glucose. Subsequently, the sterols and total carbohydrates extracted from the biomass were quantified through a spectrophotometric analysis. To optimize these two response variables, similar values are required for aeration (1.2 vvm) and agitation (60 rpm), while the glucose concentration was $16.32 \mathrm{~g} / \mathrm{L}$ and $19.6 \mathrm{~g} / \mathrm{L}$ for sterols and total polysaccharides respectively.

Keywords: Fermentation in liquid state, macromycete, Lentinula edodes, sterols, polysaccharides.

\section{Declarations}

\section{Funding}

This research was supported by Vicerrectoría de Investigación de la Universidad Nacional de Colombia, Dirección de Investigación (DIB) and the Facultad de Ciencias de la sede Bogotá de la Universidad Nacional de Colombia (Proyecto 41634).

\section{Conflict of interest}

The authors declare that they have not conflict of interest.

\section{Availability of data and material}


The data that support the findings of this study are available from the corresponding author, [author initials], upon reasonable request.

\section{Code availability}

Not applicable

\section{Authors contribution}

Juan C. Serrato-Bermudez and Carolina Chegwin-Angarita supervised, designed the research and data analyses. Robinson Bello-Forero conducted the experiments, data analysis and original text. All authors revised and approved the manuscript.

\section{Introduction}

The Lentinula edodes (Shitake) mushroom is one of the most widely used basidiomycetes in traditional Chinese medicine and in East Asian countries, due to its medicinal and nutritional properties (1), it also has potential use in the production of pharmaceuticals, functional foods and dietary supplements, among others (2).

These properties are attributed to different compounds that may be present in the fruiting body, the mycelium, or be excreted to the culture medium (3). Among the main bioactive compounds are polysaccharides, sterols, terpenoids, polyphenolic compounds, and flavonoids that gives a wide spectrum of use based on their biological activities such as antioxidant, hypercholesterolemic, anticancer, antibiotic, antiparasitic, and immunomodulatory. In addition, these compounds generally cause less toxic effects in the human body than the products obtained by synthesis (4-5).

The traditional cultivation of mushrooms to obtain the fruiting body was initially developed to provide a nutrient-rich food source. However, it has several disadvantages that make it inefficient, for example, it is a slow process and the variables that favor the growth of the fungus are very difficult to control, which significantly affects the standardization of the final product (5). For these reasons, biotechnological fermentation techniques have grown in popularity due to their low-cost and environmental advantages, modifying and refining old techniques to maximize productivity (6). Additionally, the isolation of secondary metabolites produced by these organisms have made Solid State Fermentation (SSF) and Liquid State Fermentation (LSF) the most suitable techniques for the production of this class of bioactive compounds. Due to these drawbacks and in order to increase the production of biomass and fungimetabolites, controlled culture was developed in bioreactors using submerged and solid-state fermentation (7). Despite having several advantages compared to submerged fermentation such as low energy consumption and high volumetric production from low-cost substrates; solid-state fermentation presents problems associated with the control of variables $(\mathrm{pH}$, temperature, aeration, water content and oxygen transfer), which has not allowed working with larger-scale bioreactors as a result of the complexity in their design (8-9). On the other hand, in submerged fermentation these factors can be controlled more efficiently, a fact that allows standardizing and optimizing the production of biomass and metabolites of interest. Taking into account the bioprospective potential that the fungus 
L. edodes has, it is possible to develop new products in search of benefits for the treatment of different diseases through bioreactor culture (7-8).

There are some studies focused on optimizing the conditions for the production of biomass and metabolites of fungi (10-18). However, there are few reports about the cultivation of this fungus in bioreactors, and most of them have focused on obtaining a particular type of compounds $(10,11,13)$. Considering that, it was possible to determine the optimal operating conditions (aeration, agitation and glucose concentration) for the fermentation in liquid state of the fungus Lentinula edodes in a stirred bioreactor, taking into account the importance of obtaining a balance between biomass production and its composition.

\section{Materials and methods}

The biomass obtained by LSF of Lentinula edodes in a bioreactor under each of the different combinations of agitation, aeration and glucose content, was subjected to exhaustive extraction processes with solvents of different polarity (dichloromethane, ethanol and water) to subsequently quantify the metabolites of interest by colorimetric tests

\subsection{Fungal material and strain conditioning}

The strain of the fungus L. edodes was bought from the company Mushroom Shroom Supply (USA). The activation was carried out in Petri dishes using Potato Dextrose Agar (PDA) medium, in conditions of total darkness and maintaining a temperature of $25 \pm 1{ }^{\circ} \mathrm{C}$ for a period of 10 to 15 days (2), in a WISD incubator model WIG-155.

\subsection{Liquid State Fermentation (LSF)}

The LSF was carried out in the following phases; preinoculum, inoculum and bioreactor culture. GPY medium (Glucose-Peptone-Yeast Extract) was used in each of them, based on previous studies carried out by 2 and 19. The GPY medium was composed of ( $\mathrm{g} / \mathrm{L}$ ) glucose (20), peptone (2.5), yeast extract (2.5) and the $\mathrm{pH}$ was adjusted to 5.0 (Feng et al., 2010). To obtain the preinoculum and inoculum, $100 \mathrm{~mL}$ of medium served in $250 \mathrm{~mL}$ flasks were used, while $2100 \mathrm{~mL}$ of medium were needed for the culture in the bioreactor. The fermentation conditions such as temperature, initial $\mathrm{pH}$, growth period, peptone concentration and yeast extract were kept constant at $25^{\circ} \mathrm{C}, 5.0,5$ days and $2.5 \mathrm{~g} / \mathrm{L}$ respectively $(10,11,20)$.

\subsubsection{Preinoculum}

The preinoculum was obtained by adding 15 discs of $0.5-1.0 \mathrm{~cm}$ in diameter to each of the flasks, maintaining the conditions previously established by (21) for submerged fermentation. The disks were made up of mycelium and agar (22) from the Petri dishes from the conditioning stage. The flasks were placed on an orbital shaker at $120 \mathrm{rpm}$ and $25^{\circ} \mathrm{C}$ for a period of 10 days to favor the formation of pellets $(23,24)$.

\subsubsection{Inoculum}


The biomass produced in the pre-inoculum was filtered, $1.5 \mathrm{~g}$ of wet mycelium produced in the pre-inoculum were weighed, transferred to flasks with GPY culture medium and cultured under the same pre-inoculum conditions for a period of 5 days.

The content of four flasks was used as inoculum for the bioreactor, the others were filtered and lyophilized to determine the amount of biomass added.

\subsubsection{Bioreactor}

The culture was carried out in a $3 \mathrm{~L}$ Applikon bioreactor, with agitation and a flute aeration system. The bioreactor was fed with 400 $\mathrm{mL}$ of the inoculum $(16 \% \mathrm{v} / \mathrm{v})$ and was kept at a temperature of $25 \pm 1^{\circ} \mathrm{C}$ for a period of 5 days. The assembly and inoculation were carried out in an ESCO model LHS-5CG-F9 laminar flow cabinet, to ensure aseptic conditions, and both the culture medium and the bioreactor were sterilized in an autoclave at a temperature of $121^{\circ} \mathrm{C}$. The specific conditions of each of the treatments are presented in table 1. A total of 15 experiments with three replicas at the central point were performed and carried out randomly.

\subsection{Biomass and metabolites optimization process}

A response surface methodology (RSM) was used to maximize the production of biomass and intrametabolites (sterols and total polysaccharides) using three factors (agitation, aeration and glucose concentration). A Box-Behnken design was selected to analyze the effect of the three factors with three levels (Error! Reference source not found.), it is described in Error! Reference source not found..

The relationship between the factors and the response variables was adjusted to the following second-order polynomial equation:

$$
Y_{i}=\beta_{0}+\sum_{i=1}^{k} \beta_{i} X_{i}+\sum_{i=1}^{k} \beta_{i i} X_{i}^{2}+\sum_{i<j}^{k} \sum \beta_{i j} X_{i} X_{j}
$$

where $\mathrm{Yi}$ is the predicted response, the subscripts $\mathrm{i}$ and $\mathrm{j}$ takes values from 1 to the number of variables, $\beta 0$ is a constant, $\beta i$ is the linear coefficient, $\beta_{i i}$ is the quadratic coefficient, $\beta_{i j}$ is the cross product coefficient, $k$ is the number of factors, and $x_{i}$ and $x_{j}$ are the dimensionless coded values of the investigated variables.

\section{Results and discussion}

\subsection{Biomass production optimization}

The results obtained in the experimental design for biomass production are presented in Error! Reference source not found..

In the data, a significant variation in biomass can be observed from $1.3463 \mathrm{~g}$ dry biomass / g BAB to $8.1534 \mathrm{~g}$ dry biomass / g BAB, depending on the fermentation conditions in the bioreactor. To evaluate the optimal conditions and the effect of significant factors on biomass production, a statistical analysis of variance (ANOVA) was carried out. Additionally, the $P$-value was used as a tool to determine the significance of the factors and their interactions, the smaller the $P$-value, the more significant the corresponding factor 
was (Li et al., 2012). As shown in Error! Reference source not found., the experimental data fit a quadratic model. The ANOVA indicated that the quadratic regression model for the response surface was statistically significant $(P=0.008)$ with an $F$ value of 11.00 , for a significance level of $95 \%$. The multiple regression equation that describes the behavior of biomass $(Y)$ as a function of $\left({ }_{x 1}\right)$ glucose concentration, $(x 2)$ aeration and $(x 3)$ agitation, obtained from the experimental data, was given by the following expression: $Y_{\text {Biomass }}=3.246+1.346 x_{1}+0.742 x_{2}-0.059 x_{3}-0.812 x_{1}^{2}+1.958 x_{2}^{2}+0.482 x_{3}^{2}-1.189 x_{1} x_{2}+0.271 x_{1} x_{3}-0.988 x_{2} x_{3}$ A higher absolute value of the coefficient in the regression equation indicates that the factor has a greater effect on biomass production, in contrast, a value close to zero represents a low or no effect of the independent variable on the response (32). According to the ANOVA, the terms that have a high significant effect on biomass production were $x_{1}$ and $x_{2}^{2}(P=0.003), x_{1} x_{2}$ $(P=0.018), x_{2}(P=0.029)$ and $x_{2} x_{3}(P=0.035)$. Through the regression analysis of the data, it is observed that the coefficient of determination (R2) for equation (1) was 0.9519 , which indicates that $95.19 \%$ of the variation for biomass production can be explained by the model and only $4.81 \%$ is attributed to experimental error. Additionally, the statistical results suggest that the previous regression model can adequately predict the biomass values within the range of the variables studied $(R=0.9756)$. This validity of the model is confirmed with the lack of fit, whose $P$-value was $0.109(>0.05)$, which implies that the lack of fit is not significant and therefore the pure error is not due to noise.

Fig 1 show the effect of the factors and their interactions on the biomass in the region delimited by the studied levels of each factor, in order to determine the optimal conditions to maximize the response. The 3D surfaces and their respective level curves (Fig $\mathbf{1}(\mathrm{a})$ ) represent the effect of the interaction between glucose concentration and aeration on biomass production, when stirring is maintained at $60 \mathrm{rpm}$. From this graph, it can be inferred that by increasing the glucose concentration and maintaining aeration at values close to or greater than 1.2 vvm, the biomass yield could be significantly increased. A similar behavior is observed in Fig $\mathbf{1}(\mathrm{b})$ where it is appreciated that slight changes in glucose concentration favor the mycelial growth of the fungus. It is expected for an aerobic organism, considering the low solubility of oxygen in aqueous media, the possible limitation to the mass transfer from the gas phase to the culture medium, and from this to the interior of the mycelium. It could limit not only the growth rate of the fungus but also the production of metabolites of interest (33). In contrast, a study revealed that aeration values between 1 and 1.5 vvm cause a considerable decrease in the cell growth of $P$. ostreatus (34). This could indicate that, as mentioned by (33), depending on the fermentation conditions, the microorganism establishes a metabolic route for the production of a particular compound, being necessary to guarantee a certain oxygen transfer rate under certain operating conditions. Meanwhile, it is evident that the agitation in the analyzed interval does not have an important effect on the biomass production (Fig $\mathbf{1 b}$ ) and (c)). These results showed that the maximum amount of biomass $(7.48 \mathrm{~g})$ for $L$. edodes was obtained with a glucose concentration of $21.97 \mathrm{~g} / \mathrm{L}$, aeration of $1.2 \mathrm{vvm}$ and a stirring of $60 \mathrm{rpm}$. 
Fig 1 Effect of variables on biomass production

Glucose appreciably promotes mycelial growth, a result that coincides with that reported by (11) who indicate that this is the most effective carbon source for L. edodes in submerged fermentation. These authors used a similar experimental design to analyze the glucose concentration, the yeast extract concentration and the $\mathrm{pH}$ in an airlift reactor (100 $\mathrm{L})$, finding that a glucose concentration of $15.4 \mathrm{~g} / \mathrm{L}$ maximizes the production of mycelial biomass. This difference can be attributed to many factors, including strain, operating conditions, reactor type, and culture medium. (35) who worked with Pleurotus ostreatus agree that the highest biomass production is found when the glucose concentration increases $(>25 \mathrm{~g} / \mathrm{L})$, however, they observed an inverse effect on the production of phenolic compounds, since the maximum values of these metabolites were reached at concentrations lower than $20 \mathrm{~g} / \mathrm{L}$.

\subsection{Sterol production optimization}

Sterols are triterpenoidal compounds commonly present in edible macromycete fungi to which a wide variety of proven biological activities are attributed (36). The regression model that predicts the production of sterols is given by the following equation:

$Y_{\text {Esteroles }}=3.10+1.266 x_{1}+1.103 x_{2}-0.195 x_{3}-1.66 x_{1}^{2}+3.05 x_{2}^{2}+1.62 x_{3}^{2}-3.11 x_{1} x_{2}+0.73 x_{1} x_{3}-0.06 x_{2} x_{3}$

According to the results of the ANOVA, only two factors have a significant effect on this response $(P<0,05) ; x_{1} x_{2}(P=0.033)$, $x_{2}^{2}(P=0.040)$. Additionally, the multiple correlation coefficient $\mathrm{R} 2$ was 0.8402 , which indicates that $84.02 \%$ of the variation in the production of sterols can be explained by the variation between treatments. Meanwhile, since the multiple correlation coefficient $\mathrm{R}$ (0.9166) has a value close to 1 , the experimental concentration of sterols can be predicted by the regression model. As can be seen, the biosynthesis of sterols responds to both glucose concentration and aeration, since slight changes in any of these variables can generate a drastic increase or decrease in its production (Error! Not a valid bookmark self-reference. (a)).

Fig 2 Effect of variables on sterols production

In Glucose appreciably promotes mycelial growth, a result that coincides with that reported by (11) who indicate that this is the most effective carbon source for $L$. edodes in submerged fermentation. These authors used a similar experimental design to analyze the glucose concentration, the yeast extract concentration and the $\mathrm{pH}$ in an airlift reactor (100 $\mathrm{L})$, finding that a glucose concentration of $15.4 \mathrm{~g} / \mathrm{L}$ maximizes the production of mycelial biomass. This difference can be attributed to many factors, including strain, operating conditions, reactor type, and culture medium. (35) who worked with Pleurotus ostreatus agree that the highest biomass production is found when the glucose concentration increases (>25 g/ L), however, they observed an inverse effect on the production of phenolic compounds, since the maximum values of these metabolites were reached at concentrations lower than $20 \mathrm{~g} / \mathrm{L}$.

\subsection{Sterol production optimization}

Sterols are triterpenoidal compounds commonly present in edible macromycete fungi to which a wide variety of proven biological activities are attributed (36). The regression model that predicts the production of sterols is given by the following equation: 
$Y_{\text {Esteroles }}=3.10+1.266 x_{1}+1.103 x_{2}-0.195 x_{3}-1.66 x_{1}^{2}+3.05 x_{2}^{2}+1.62 x_{3}^{2}-3.11 x_{1} x_{2}+0.73 x_{1} x_{3}-0.06 x_{2} x_{3}$

According to the results of the ANOVA, only two factors have a significant effect on this response $(P<0,05) ; x_{1} x_{2}(P=0.033)$, $x_{2}^{2}(P=0.040)$. Additionally, the multiple correlation coefficient R2 was 0.8402 , which indicates that $84.02 \%$ of the variation in the production of sterols can be explained by the variation between treatments. Meanwhile, since the multiple correlation coefficient $R$ (0.9166) has a value close to 1 , the experimental concentration of sterols can be predicted by the regression model. As can be seen, the biosynthesis of sterols responds to both glucose concentration and aeration, since slight changes in any of these variables can generate a drastic increase or decrease in its production (Error! Not a valid bookmark self-reference. (a)).

Fig 2 it is observed that at glucose concentrations between 16 and $22 \mathrm{~g} / \mathrm{L}$ and aeration levels higher than $1.2 \mathrm{vvm}$, a maximum of sterols can be produced, while values outside these ranges cause an appreciable decrease. Stirring, on the other hand, has a less marked effect, since the increase in the amount of sterols is reached at low values of this factor, as indicated in Glucose appreciably promotes mycelial growth, a result that coincides with that reported by (11) who indicate that this is the most effective carbon source for L. edodes in submerged fermentation. These authors used a similar experimental design to analyze the glucose concentration, the yeast extract concentration and the $\mathrm{pH}$ in an airlift reactor $(100 \mathrm{~L})$, finding that a glucose concentration of $15.4 \mathrm{~g} / \mathrm{L}$ maximizes the production of mycelial biomass. This difference can be attributed to many factors, including strain, operating conditions, reactor type, and culture medium. (35) who worked with Pleurotus ostreatus agree that the highest biomass production is found when the glucose concentration increases ( $>25 \mathrm{~g} / \mathrm{L}$ ), however, they observed an inverse effect on the production of phenolic compounds, since the maximum values of these metabolites were reached at concentrations lower than $20 \mathrm{~g} / \mathrm{L}$.

\subsection{Sterol production optimization}

Sterols are triterpenoidal compounds commonly present in edible macromycete fungi to which a wide variety of proven biological activities are attributed (36). The regression model that predicts the production of sterols is given by the following equation:

$Y_{\text {Esteroles }}=3.10+1.266 x_{1}+1.103 x_{2}-0.195 x_{3}-1.66 x_{1}^{2}+3.05 x_{2}^{2}+1.62 x_{3}^{2}-3.11 x_{1} x_{2}+0.73 x_{1} x_{3}-0.06 x_{2} x_{3}$ According to the results of the ANOVA, only two factors have a significant effect on this response $(P<0,05) ; x_{1} x_{2}(P=0.033)$, $x_{2}^{2}(P=0.040)$. Additionally, the multiple correlation coefficient $\mathrm{R} 2$ was 0.8402 , which indicates that $84.02 \%$ of the variation in the production of sterols can be explained by the variation between treatments. Meanwhile, since the multiple correlation coefficient $R$ (0.9166) has a value close to 1 , the experimental concentration of sterols can be predicted by the regression model. As can be seen, the biosynthesis of sterols responds to both glucose concentration and aeration, since slight changes in any of these variables can generate a drastic increase or decrease in its production (Error! Not a valid bookmark self-reference. (a)).

Fig 2 (b) and (c). 
Regarding to a comparison of these results with previous studies, there are no similar reports for the culture of Lentinula edodes in a

bioreactor. Results can only be contrasted with studies carried out with other types of macromycete fungi in which the agitation is considered an important parameter for the production of exometabolites, the transfer of oxygen and heat, as well as the shear stress, are relevant aspects to determine the morphology of the mycelium $(7,8,14,37)$.

Meanwhile, the maximum sterol production predicted by the model was $10.12 \mathrm{mg} / \mathrm{g}$ BAB under the following conditions: glucose concentration $16.32 \mathrm{~g} / \mathrm{L}$, aeration of $1.2 \mathrm{vvm}$ and stirring at $60 \mathrm{rpm}$.

\subsection{Optimization of polysaccharide production}

According to the results, there is a considerable variation in the amount of polysaccharides obtained in each of the treatments. The following expression describes the interaction between the factors on total polysaccharides:

$Y_{\text {Polysacharides }}=64.7-28.3 x_{1}+3.6 x_{2}-25.8 x_{3}-51.3 x_{1}^{2}+16.3 x_{2}^{2}+31.8 x_{3}^{2}-14 x_{1} x_{2}+25.2 x_{1} x_{3}-93.7 x_{2} x_{3}$

The value of $\mathrm{R}^{2}$ was 0.9315 , only $6.85 \%$ of the total variation cannot be explained by the model. On the other hand, because the $P$ value for the quadratic regression model was less than $0.05(P=0.019)$, it is possible to ensure that the equation model adequately predicts the production of polysaccharides over the studied region. The only terms that had a significant effect were $x_{1}^{2}(P<0.025)$ and $x_{2} x_{3}(P<0.002)$.

Fig 3 Effect of variables on polysaccharides production

In Glucose appreciably promotes mycelial growth, a result that coincides with that reported by (11) who indicate that this is the most effective carbon source for L. edodes in submerged fermentation. These authors used a similar experimental design to analyze the glucose concentration, the yeast extract concentration and the $\mathrm{pH}$ in an airlift reactor (100 L), finding that a glucose concentration of $15.4 \mathrm{~g} / \mathrm{L}$ maximizes the production of mycelial biomass. This difference can be attributed to many factors, including strain, operating conditions, reactor type, and culture medium. (35) who worked with Pleurotus ostreatus agree that the highest biomass production is found when the glucose concentration increases ( $>25 \mathrm{~g} / \mathrm{L})$, however, they observed an inverse effect on the production of phenolic compounds, since the maximum values of these metabolites were reached at concentrations lower than $20 \mathrm{~g} / \mathrm{L}$.

\subsection{Sterol production optimization}

Sterols are triterpenoidal compounds commonly present in edible macromycete fungi to which a wide variety of proven biological activities are attributed (36). The regression model that predicts the production of sterols is given by the following equation:

$Y_{\text {Esteroles }}=3.10+1.266 x_{1}+1.103 x_{2}-0.195 x_{3}-1.66 x_{1}^{2}+3.05 x_{2}^{2}+1.62 x_{3}^{2}-3.11 x_{1} x_{2}+0.73 x_{1} x_{3}-0.06 x_{2} x_{3}$

According to the results of the ANOVA, only two factors have a significant effect on this response $(P<0,05) ; x_{1} x_{2}(P=0.033)$, $x_{2}^{2}(P=0.040)$. Additionally, the multiple correlation coefficient $\mathrm{R} 2$ was 0.8402 , which indicates that $84.02 \%$ of the variation in the production of sterols can be explained by the variation between treatments. Meanwhile, since the multiple correlation coefficient $\mathrm{R}$ 
(0.9166) has a value close to 1 , the experimental concentration of sterols can be predicted by the regression model. As can be seen, the biosynthesis of sterols responds to both glucose concentration and aeration, since slight changes in any of these variables can generate a drastic increase or decrease in its production (Error! Not a valid bookmark self-reference. (a)).

Fig 2 it is observed that at glucose concentrations between 16 and $22 \mathrm{~g} / \mathrm{L}$ and aeration levels higher than $1.2 \mathrm{vvm}$, a maximum of sterols can be produced, while values outside these ranges cause an appreciable decrease. Stirring, on the other hand, has a less marked effect, since the increase in the amount of sterols is reached at low values of this factor, as indicated in Glucose appreciably promotes mycelial growth, a result that coincides with that reported by (11) who indicate that this is the most effective carbon source for L. edodes in submerged fermentation. These authors used a similar experimental design to analyze the glucose concentration, the yeast extract concentration and the $\mathrm{pH}$ in an airlift reactor $(100 \mathrm{~L})$, finding that a glucose concentration of $15.4 \mathrm{~g} / \mathrm{L}$ maximizes the production of mycelial biomass. This difference can be attributed to many factors, including strain, operating conditions, reactor type, and culture medium. (35) who worked with Pleurotus ostreatus agree that the highest biomass production is found when the glucose concentration increases (> $25 \mathrm{~g} / \mathrm{L}$ ), however, they observed an inverse effect on the production of phenolic compounds, since the maximum values of these metabolites were reached at concentrations lower than $20 \mathrm{~g} / \mathrm{L}$.

\subsection{Sterol production optimization}

Sterols are triterpenoidal compounds commonly present in edible macromycete fungi to which a wide variety of proven biological activities are attributed (36). The regression model that predicts the production of sterols is given by the following equation:

$Y_{\text {Esteroles }}=3.10+1.266 x_{1}+1.103 x_{2}-0.195 x_{3}-1.66 x_{1}^{2}+3.05 x_{2}^{2}+1.62 x_{3}^{2}-3.11 x_{1} x_{2}+0.73 x_{1} x_{3}-0.06 x_{2} x_{3}$

According to the results of the ANOVA, only two factors have a significant effect on this response $(P<0,05) ; x_{1} x_{2}(P=0.033)$, $x_{2}^{2}(P=0.040)$. Additionally, the multiple correlation coefficient $\mathrm{R} 2$ was 0.8402, which indicates that $84.02 \%$ of the variation in the production of sterols can be explained by the variation between treatments. Meanwhile, since the multiple correlation coefficient $\mathrm{R}$ (0.9166) has a value close to 1 , the experimental concentration of sterols can be predicted by the regression model. As can be seen, the biosynthesis of sterols responds to both glucose concentration and aeration, since slight changes in any of these variables can generate a drastic increase or decrease in its production (Error! Not a valid bookmark self-reference. (a)).

Fig 2(b) and (c).

Regarding to a comparison of these results with previous studies, there are no similar reports for the culture of Lentinula edodes in a bioreactor. Results can only be contrasted with studies carried out with other types of macromycete fungi in which the agitation is considered an important parameter for the production of exometabolites, the transfer of oxygen and heat, as well as the shear stress, are relevant aspects to determine the morphology of the mycelium $(7,8,14,37)$. 
Meanwhile, the maximum sterol production predicted by the model was $10.12 \mathrm{mg} / \mathrm{g}$ BAB under the following conditions: glucose concentration $16.32 \mathrm{~g} / \mathrm{L}$, aeration of $1.2 \mathrm{vvm}$ and stirring at $60 \mathrm{rpm}$.

\subsection{Optimization of polysaccharide production}

According to the results, there is a considerable variation in the amount of polysaccharides obtained in each of the treatments. The following expression describes the interaction between the factors on total polysaccharides:

$Y_{\text {Polysacharides }}=64.7-28.3 x_{1}+3.6 x_{2}-25.8 x_{3}-51.3 x_{1}^{2}+16.3 x_{2}^{2}+31.8 x_{3}^{2}-14 x_{1} x_{2}+25.2 x_{1} x_{3}-93.7 x_{2} x_{3}$

The value of $\mathrm{R}^{2}$ was 0.9315 , only $6.85 \%$ of the total variation cannot be explained by the model. On the other hand, because the $P$ value for the quadratic regression model was less than $0.05(P=0.019)$, it is possible to ensure that the equation model adequately predicts the production of polysaccharides over the studied region. The only terms that had a significant effect were $x_{1}^{2}(P<0.025)$ and $x_{2} x_{3}(P<0.002)$

Fig 3 shows the surface graphs in which the effect of the interaction between two independent variables on the amount of polysaccharides is appreciated. Adjusting the agitation at $60 \mathrm{rpm}$ (In Glucose appreciably promotes mycelial growth, a result that coincides with that reported by (11) who indicate that this is the most effective carbon source for $L$. edodes in submerged fermentation. These authors used a similar experimental design to analyze the glucose concentration, the yeast extract concentration and the $\mathrm{pH}$ in an airlift reactor $(100 \mathrm{~L})$, finding that a glucose concentration of $15.4 \mathrm{~g} / \mathrm{L}$ maximizes the production of mycelial biomass. This difference can be attributed to many factors, including strain, operating conditions, reactor type, and culture medium. (35) who worked with Pleurotus ostreatus agree that the highest biomass production is found when the glucose concentration increases ( $>25$ $\mathrm{g} / \mathrm{L})$, however, they observed an inverse effect on the production of phenolic compounds, since the maximum values of these metabolites were reached at concentrations lower than $20 \mathrm{~g} / \mathrm{L}$.

\subsection{Sterol production optimization}

Sterols are triterpenoidal compounds commonly present in edible macromycete fungi to which a wide variety of proven biological activities are attributed (36). The regression model that predicts the production of sterols is given by the following equation:

$Y_{\text {Esteroles }}=3.10+1.266 x_{1}+1.103 x_{2}-0.195 x_{3}-1.66 x_{1}^{2}+3.05 x_{2}^{2}+1.62 x_{3}^{2}-3.11 x_{1} x_{2}+0.73 x_{1} x_{3}-0.06 x_{2} x_{3}$

According to the results of the ANOVA, only two factors have a significant effect on this response $(P<0,05) ; x_{1} x_{2}(P=0.033)$, $x_{2}^{2}(P=0.040)$. Additionally, the multiple correlation coefficient R2 was 0.8402 , which indicates that $84.02 \%$ of the variation in the production of sterols can be explained by the variation between treatments. Meanwhile, since the multiple correlation coefficient $\mathrm{R}$ (0.9166) has a value close to 1 , the experimental concentration of sterols can be predicted by the regression model. As can be seen, the biosynthesis of sterols responds to both glucose concentration and aeration, since slight changes in any of these variables can generate a drastic increase or decrease in its production (Error! Not a valid bookmark self-reference. (a)). 
Fig 2 it is observed that at glucose concentrations between 16 and $22 \mathrm{~g} / \mathrm{L}$ and aeration levels higher than $1.2 \mathrm{vvm}$, a maximum of sterols can be produced, while values outside these ranges cause an appreciable decrease. Stirring, on the other hand, has a less marked effect, since the increase in the amount of sterols is reached at low values of this factor, as indicated in Glucose appreciably promotes mycelial growth, a result that coincides with that reported by (11) who indicate that this is the most effective carbon source for L. edodes in submerged fermentation. These authors used a similar experimental design to analyze the glucose concentration, the yeast extract concentration and the $\mathrm{pH}$ in an airlift reactor $(100 \mathrm{~L})$, finding that a glucose concentration of $15.4 \mathrm{~g} / \mathrm{L}$ maximizes the production of mycelial biomass. This difference can be attributed to many factors, including strain, operating conditions, reactor type, and culture medium. (35) who worked with Pleurotus ostreatus agree that the highest biomass production is found when the glucose concentration increases (> $25 \mathrm{~g} / \mathrm{L}$ ), however, they observed an inverse effect on the production of phenolic compounds, since the maximum values of these metabolites were reached at concentrations lower than $20 \mathrm{~g} / \mathrm{L}$.

\subsection{Sterol production optimization}

Sterols are triterpenoidal compounds commonly present in edible macromycete fungi to which a wide variety of proven biological activities are attributed (36). The regression model that predicts the production of sterols is given by the following equation:

$Y_{\text {Esteroles }}=3.10+1.266 x_{1}+1.103 x_{2}-0.195 x_{3}-1.66 x_{1}^{2}+3.05 x_{2}^{2}+1.62 x_{3}^{2}-3.11 x_{1} x_{2}+0.73 x_{1} x_{3}-0.06 x_{2} x_{3}$

According to the results of the ANOVA, only two factors have a significant effect on this response $(P<0,05) ; x_{1} x_{2}(P=0.033)$, $x_{2}^{2}(P=0.040)$. Additionally, the multiple correlation coefficient R2 was 0.8402 , which indicates that $84.02 \%$ of the variation in the production of sterols can be explained by the variation between treatments. Meanwhile, since the multiple correlation coefficient $\mathrm{R}$ (0.9166) has a value close to 1 , the experimental concentration of sterols can be predicted by the regression model. As can be seen, the biosynthesis of sterols responds to both glucose concentration and aeration, since slight changes in any of these variables can generate a drastic increase or decrease in its production (Error! Not a valid bookmark self-reference. (a)).

Fig 2(b) and (c).

Regarding to a comparison of these results with previous studies, there are no similar reports for the culture of Lentinula edodes in a bioreactor. Results can only be contrasted with studies carried out with other types of macromycete fungi in which the agitation is considered an important parameter for the production of exometabolites, the transfer of oxygen and heat, as well as the shear stress, are relevant aspects to determine the morphology of the mycelium $(7,8,14,37)$.

Meanwhile, the maximum sterol production predicted by the model was $10.12 \mathrm{mg} / \mathrm{g}$ BAB under the following conditions: glucose concentration $16.32 \mathrm{~g} / \mathrm{L}$, aeration of $1.2 \mathrm{vvm}$ and stirring at $60 \mathrm{rpm}$.

\subsection{Optimization of polysaccharide production}


According to the results, there is a considerable variation in the amount of polysaccharides obtained in each of the treatments. The

following expression describes the interaction between the factors on total polysaccharides:

$Y_{\text {Polysacharides }}=64.7-28.3 x_{1}+3.6 x_{2}-25.8 x_{3}-51.3 x_{1}^{2}+16.3 x_{2}^{2}+31.8 x_{3}^{2}-14 x_{1} x_{2}+25.2 x_{1} x_{3}-93.7 x_{2} x_{3}$

The value of $\mathrm{R}^{2}$ was 0.9315 , only $6.85 \%$ of the total variation cannot be explained by the model. On the other hand, because the $P$ value for the quadratic regression model was less than $0.05(P=0.019)$, it is possible to ensure that the equation model adequately predicts the production of polysaccharides over the studied region. The only terms that had a significant effect were $x_{1}^{2}(P<0.025)$ and $x_{2} x_{3}(P<0.002)$.

Fig $3(\mathrm{a})$ ), the production of these compounds tends to increase for glucose values between 18 and $24 \mathrm{~g} / \mathrm{L}$ and aerations greater than 1 vvm. From In Glucose appreciably promotes mycelial growth, a result that coincides with that reported by (11) who indicate that this is the most effective carbon source for L. edodes in submerged fermentation. These authors used a similar experimental design to analyze the glucose concentration, the yeast extract concentration and the $\mathrm{pH}$ in an airlift reactor (100 L), finding that a glucose concentration of $15.4 \mathrm{~g} / \mathrm{L}$ maximizes the production of mycelial biomass. This difference can be attributed to many factors, including strain, operating conditions, reactor type, and culture medium. (35) who worked with Pleurotus ostreatus agree that the highest biomass production is found when the glucose concentration increases (> $25 \mathrm{~g} / \mathrm{L}$ ), however, they observed an inverse effect on the production of phenolic compounds, since the maximum values of these metabolites were reached at concentrations lower than $20 \mathrm{~g}$ /L.

\subsection{Sterol production optimization}

Sterols are triterpenoidal compounds commonly present in edible macromycete fungi to which a wide variety of proven biological activities are attributed (36). The regression model that predicts the production of sterols is given by the following equation:

$Y_{\text {Esteroles }}=3.10+1.266 x_{1}+1.103 x_{2}-0.195 x_{3}-1.66 x_{1}^{2}+3.05 x_{2}^{2}+1.62 x_{3}^{2}-3.11 x_{1} x_{2}+0.73 x_{1} x_{3}-0.06 x_{2} x_{3}$

According to the results of the ANOVA, only two factors have a significant effect on this response $(P<0,05) ; x_{1} x_{2}(P=0.033)$, $x_{2}^{2}(P=0.040)$. Additionally, the multiple correlation coefficient $\mathrm{R} 2$ was 0.8402, which indicates that $84.02 \%$ of the variation in the production of sterols can be explained by the variation between treatments. Meanwhile, since the multiple correlation coefficient $\mathrm{R}$ (0.9166) has a value close to 1 , the experimental concentration of sterols can be predicted by the regression model. As can be seen, the biosynthesis of sterols responds to both glucose concentration and aeration, since slight changes in any of these variables can generate a drastic increase or decrease in its production (Error! Not a valid bookmark self-reference. (a)).

Fig 2 it is observed that at glucose concentrations between 16 and $22 \mathrm{~g} / \mathrm{L}$ and aeration levels higher than $1.2 \mathrm{vvm}$, a maximum of sterols can be produced, while values outside these ranges cause an appreciable decrease. Stirring, on the other hand, has a less marked effect, since the increase in the amount of sterols is reached at low values of this factor, as indicated in Glucose appreciably 
promotes mycelial growth, a result that coincides with that reported by (11) who indicate that this is the most effective carbon source for L. edodes in submerged fermentation. These authors used a similar experimental design to analyze the glucose concentration, the yeast extract concentration and the $\mathrm{pH}$ in an airlift reactor $(100 \mathrm{~L})$, finding that a glucose concentration of $15.4 \mathrm{~g} / \mathrm{L}$ maximizes the production of mycelial biomass. This difference can be attributed to many factors, including strain, operating conditions, reactor type, and culture medium. (35) who worked with Pleurotus ostreatus agree that the highest biomass production is found when the glucose concentration increases ( $>25 \mathrm{~g} / \mathrm{L}$ ), however, they observed an inverse effect on the production of phenolic compounds, since the maximum values of these metabolites were reached at concentrations lower than $20 \mathrm{~g} / \mathrm{L}$.

\subsection{Sterol production optimization}

Sterols are triterpenoidal compounds commonly present in edible macromycete fungi to which a wide variety of proven biological activities are attributed (36). The regression model that predicts the production of sterols is given by the following equation:

$Y_{\text {Esteroles }}=3.10+1.266 x_{1}+1.103 x_{2}-0.195 x_{3}-1.66 x_{1}^{2}+3.05 x_{2}^{2}+1.62 x_{3}^{2}-3.11 x_{1} x_{2}+0.73 x_{1} x_{3}-0.06 x_{2} x_{3}$

According to the results of the ANOVA, only two factors have a significant effect on this response $(P<0,05) ; x_{1} x_{2}(P=0.033)$, $x_{2}^{2}(P=0.040)$. Additionally, the multiple correlation coefficient R2 was 0.8402 , which indicates that $84.02 \%$ of the variation in the production of sterols can be explained by the variation between treatments. Meanwhile, since the multiple correlation coefficient $\mathrm{R}$ (0.9166) has a value close to 1 , the experimental concentration of sterols can be predicted by the regression model. As can be seen, the biosynthesis of sterols responds to both glucose concentration and aeration, since slight changes in any of these variables can generate a drastic increase or decrease in its production (Error! Not a valid bookmark self-reference. (a)).

Fig 2(b) and (c).

Regarding to a comparison of these results with previous studies, there are no similar reports for the culture of Lentinula edodes in a bioreactor. Results can only be contrasted with studies carried out with other types of macromycete fungi in which the agitation is considered an important parameter for the production of exometabolites, the transfer of oxygen and heat, as well as the shear stress, are relevant aspects to determine the morphology of the mycelium $(7,8,14,37)$.

Meanwhile, the maximum sterol production predicted by the model was $10.12 \mathrm{mg} / \mathrm{g}$ BAB under the following conditions: glucose concentration $16.32 \mathrm{~g} / \mathrm{L}$, aeration of $1.2 \mathrm{vvm}$ and stirring at $60 \mathrm{rpm}$.

\subsection{Optimization of polysaccharide production}

According to the results, there is a considerable variation in the amount of polysaccharides obtained in each of the treatments. The following expression describes the interaction between the factors on total polysaccharides:

$$
Y_{\text {Polysacharides }}=64.7-28.3 x_{1}+3.6 x_{2}-25.8 x_{3}-51.3 x_{1}^{2}+16.3 x_{2}^{2}+31.8 x_{3}^{2}-14 x_{1} x_{2}+25.2 x_{1} x_{3}-93.7 x_{2} x_{3}
$$


The value of $\mathrm{R}^{2}$ was 0.9315 , only $6.85 \%$ of the total variation cannot be explained by the model. On the other hand, because the $P$ value for the quadratic regression model was less than $0.05(P=0.019)$, it is possible to ensure that the equation model adequately predicts the production of polysaccharides over the studied region. The only terms that had a significant effect were $x_{1}^{2}(P<0.025)$ and $x_{2} x_{3}(P<0.002)$.

Fig 3 (b) it can be deduced that to maximize polysaccharide biosynthesis, low stirring conditions (<60 rpm) and glucose values similar to those of sterols should be maintained, as long as the aeration remains constant at 0.85 vvm. Finally, In Glucose appreciably promotes mycelial growth, a result that coincides with that reported by (11) who indicate that this is the most effective carbon source for L. edodes in submerged fermentation. These authors used a similar experimental design to analyze the glucose concentration, the yeast extract concentration and the $\mathrm{pH}$ in an airlift reactor $(100 \mathrm{~L})$, finding that a glucose concentration of $15.4 \mathrm{~g} / \mathrm{L}$ maximizes the production of mycelial biomass. This difference can be attributed to many factors, including strain, operating conditions, reactor type, and culture medium. (35) who worked with Pleurotus ostreatus agree that the highest biomass production is found when the glucose concentration increases ( $>25 \mathrm{~g} / \mathrm{L}$ ), however, they observed an inverse effect on the production of phenolic compounds, since the maximum values of these metabolites were reached at concentrations lower than $20 \mathrm{~g} / \mathrm{L}$.

\subsection{Sterol production optimization}

Sterols are triterpenoidal compounds commonly present in edible macromycete fungi to which a wide variety of proven biological activities are attributed (36). The regression model that predicts the production of sterols is given by the following equation:

$Y_{\text {Esteroles }}=3.10+1.266 x_{1}+1.103 x_{2}-0.195 x_{3}-1.66 x_{1}^{2}+3.05 x_{2}^{2}+1.62 x_{3}^{2}-3.11 x_{1} x_{2}+0.73 x_{1} x_{3}-0.06 x_{2} x_{3}$

According to the results of the ANOVA, only two factors have a significant effect on this response $(P<0,05) ; x_{1} x_{2}(P=0.033)$, $x_{2}^{2}(P=0.040)$. Additionally, the multiple correlation coefficient $\mathrm{R} 2$ was 0.8402, which indicates that $84.02 \%$ of the variation in the production of sterols can be explained by the variation between treatments. Meanwhile, since the multiple correlation coefficient $\mathrm{R}$ (0.9166) has a value close to 1 , the experimental concentration of sterols can be predicted by the regression model. As can be seen, the biosynthesis of sterols responds to both glucose concentration and aeration, since slight changes in any of these variables can generate a drastic increase or decrease in its production (Error! Not a valid bookmark self-reference. (a)).

Fig 2 it is observed that at glucose concentrations between 16 and $22 \mathrm{~g} / \mathrm{L}$ and aeration levels higher than $1.2 \mathrm{vvm}$, a maximum of sterols can be produced, while values outside these ranges cause an appreciable decrease. Stirring, on the other hand, has a less marked effect, since the increase in the amount of sterols is reached at low values of this factor, as indicated in Glucose appreciably promotes mycelial growth, a result that coincides with that reported by (11) who indicate that this is the most effective carbon source for L. edodes in submerged fermentation. These authors used a similar experimental design to analyze the glucose concentration, the yeast extract concentration and the $\mathrm{pH}$ in an airlift reactor $(100 \mathrm{~L})$, finding that a glucose concentration of $15.4 \mathrm{~g} / \mathrm{L}$ maximizes the 
production of mycelial biomass. This difference can be attributed to many factors, including strain, operating conditions, reactor type, and culture medium. (35) who worked with Pleurotus ostreatus agree that the highest biomass production is found when the glucose concentration increases (> $25 \mathrm{~g} / \mathrm{L}$ ), however, they observed an inverse effect on the production of phenolic compounds, since the maximum values of these metabolites were reached at concentrations lower than $20 \mathrm{~g} / \mathrm{L}$.

\subsection{Sterol production optimization}

Sterols are triterpenoidal compounds commonly present in edible macromycete fungi to which a wide variety of proven biological activities are attributed (36). The regression model that predicts the production of sterols is given by the following equation:

$Y_{\text {Esteroles }}=3.10+1.266 x_{1}+1.103 x_{2}-0.195 x_{3}-1.66 x_{1}^{2}+3.05 x_{2}^{2}+1.62 x_{3}^{2}-3.11 x_{1} x_{2}+0.73 x_{1} x_{3}-0.06 x_{2} x_{3}$

According to the results of the ANOVA, only two factors have a significant effect on this response $(P<0,05) ; x_{1} x_{2}(P=0.033)$, $x_{2}^{2}(P=0.040)$. Additionally, the multiple correlation coefficient $\mathrm{R} 2$ was 0.8402, which indicates that $84.02 \%$ of the variation in the production of sterols can be explained by the variation between treatments. Meanwhile, since the multiple correlation coefficient $\mathrm{R}$ (0.9166) has a value close to 1 , the experimental concentration of sterols can be predicted by the regression model. As can be seen, the biosynthesis of sterols responds to both glucose concentration and aeration, since slight changes in any of these variables can generate a drastic increase or decrease in its production (Error! Not a valid bookmark self-reference. (a)).

Fig 2(b) and (c).

Regarding to a comparison of these results with previous studies, there are no similar reports for the culture of Lentinula edodes in a bioreactor. Results can only be contrasted with studies carried out with other types of macromycete fungi in which the agitation is considered an important parameter for the production of exometabolites, the transfer of oxygen and heat, as well as the shear stress, are relevant aspects to determine the morphology of the mycelium $(7,8,14,37)$.

Meanwhile, the maximum sterol production predicted by the model was $10.12 \mathrm{mg} / \mathrm{g}$ BAB under the following conditions: glucose concentration $16.32 \mathrm{~g} / \mathrm{L}$, aeration of $1.2 \mathrm{vvm}$ and stirring at $60 \mathrm{rpm}$.

\subsection{Optimization of polysaccharide production}

According to the results, there is a considerable variation in the amount of polysaccharides obtained in each of the treatments. The following expression describes the interaction between the factors on total polysaccharides:

$Y_{\text {Polysacharides }}=64.7-28.3 x_{1}+3.6 x_{2}-25.8 x_{3}-51.3 x_{1}^{2}+16.3 x_{2}^{2}+31.8 x_{3}^{2}-14 x_{1} x_{2}+25.2 x_{1} x_{3}-93.7 x_{2} x_{3}$

The value of $\mathrm{R}^{2}$ was 0.9315 , only $6.85 \%$ of the total variation cannot be explained by the model. On the other hand, because the $P$ value for the quadratic regression model was less than $0.05(P=0.019)$, it is possible to ensure that the equation model adequately predicts the production of polysaccharides over the studied region. The only terms that had a significant effect were $x_{1}^{2}(P<0.025)$ and $x_{2} x_{3}(P<0.002)$. 
Fig 3(c) depicts the variation of polysaccharide production when slight changes are made in the aeration and agitation; it indicates that high air flows (> $1.2 \mathrm{vvm})$ and slow agitation $(<60 \mathrm{rpm})$ are required in order to improve the production of these compounds. These results coincide with a study in which the effect of aeration on the production of IPS was evaluated for the Ganoderma lucidum fungus, in which it was found that high percentages of oxygen saturation ( $>25 \%$ ) are optimal for the production of these compounds (38). Likewise, Hsieh, Liu, Tseng, Lo, \& Yang (2006) determined that with $21 \%$ oxygen the maximum concentration of IPS is reached when working with Grifola frondosa (39).

The optimal value of total polysaccharides predicted by the model ( $243.58 \mathrm{mg} / \mathrm{g} \mathrm{BAB}$ ) is reached with $19.6 \mathrm{~g} / \mathrm{L}$ of glucose, $1.2 \mathrm{vvm}$ of aeration and $60 \mathrm{rpm}$ of agitation. Similar results were obtained by (10) who used a genetic algorithm coupled to an artificial neural network (GA-ANN) as an optimization method, and found that the maximum amount of EPS extracted from $L$. edodes mycelium was generated with a glucose concentration of $22.5 \mathrm{~g} / \mathrm{L}$, exposing the culture to UV radiation.

\section{Conclusions}

Glucose and aeration were the factors that most influenced the three response variables studied. According to the results obtained in the Box-Behnken experimental design, aeration (1.2 vvm), agitation (60 rpm) and glucose concentrations of $21.97,16.32$ and $19.6 \mathrm{~g} /$ $\mathrm{L}$ were the conditions that optimized biomass ( $7.48 \mathrm{~g} / \mathrm{g} \mathrm{BAB})$, sterols (10.12 $\mathrm{mg} / \mathrm{g} \mathrm{BAB})$ and total polysaccharides (243.58 mg / $\mathrm{g}$ $\mathrm{BAB}$ ) respectively.

The results of this research provide useful information that can serve as a reference for optimizing the culture conditions of other macromycete fungi. Additionally, these results demonstrate that the submerged fermentation of L. edodes in a bioreactor is a promising technique for the production of biomass and secondary metabolites with potential biological activities.

In addition to this, the products obtained from this cultivation method could be used to make functional foods or other products for the medical or pharmaceutical industry. The optimization method used in this research was reliable and could also be applied efficiently in other fermentation systems to increase the production of biomass and metabolites with biological activities.

\section{References}

1. Xu, X., Yan, H., Tang, J., Chen, J., \& Zhang, X. (2014a). Polysaccharides in Lentinus edodes: Isolation, Structure, Immunomodulating Activity and Future Prospective. Critical Reviews in Food Science and Nutrition, 54(4), $474-487$. https://doi.org/10.1080/10408398.2011.587616

2. Suárez, C. (2012). Utilización de la fermentación líquida de Lentinula edodes (shiitake), para la producción de metabolitos secundarios bioactivos y evaluación de su potencial empleo en la producción de un alimento funcional. Universidad Nacional de Colombia.

3. John Smith, N. R. \& R. S. (2002). Medicinal Mushrooms:Their therapeutic properties and current medicalusage with special 
emphasis on cancer treatments. University of Strathclyde.

4. Mattila, P., Suonpa, K., \& Piironen, V. (2000). Functional properties edible mushrooms Nutrition 2002. 16, 694-696.

5. Tang, Y. J., Zhu, L. W., Li, H. M., \& Li, D. S. (2007). Submerged culture of mushrooms in bioreactors - Challenges, current state-ofthe-art, and future prospects. Food Technology and Biotechnology, 45(3), 221-229.

6. Subramaniyam, R. and Vimala, R. (2012). Solid State and Submerged Fermentation for the Production of Bioactive Substances : a Comparative Study. 3(3), 480-486.

7. Petre, Marian, \& Petre, V. (2016). Biotechnology of mushroom growth throug submerged cultivation. In Mushroom Biotechnology (pp. 1-18).

8. Berovic, M., \& Podgornik, B. B. (2016). Cultivation of Medicinal Fungi in Bioreactors. Mushroom Biotechnology: Developments and Applications, 155-171. https://doi.org/10.1016/B978-0-12-802794-3.00009-6

9. Regina, M., Broetto, F., Giovannozzi-Sermanni, G., Marabotini, R., \& Peranni, C. (2008). Influence of stationary and bioreactor cultivation on Lentinula edodes (Berk) Pegler lignocellulolitic activity. Brazilian Archives of Biology and Technology, 51(2), 223-

\section{3. https://doi.org/10.1590/S1516-89132008000200001}

10. Adeeyo, A. O., Lateef, A., \& Gueguim-kana, E. B. (2016). Optimization of the Production of Extracellular Polysaccharide from the Shiitake Medicinal Mushroom Lentinus edodes ( Agaricomycetes ) Using Mutation and a Genetic Algorithm-Coupled Artiicial Neural Network (GA-ANN). (September). https://doi.org/10.1615/IntJMedMushrooms.v18.i7.20

11. Feng, Y. L., Li, W. Q., Wu, X. Q., Cheng, J. W., \& Ma, S. Y. (2010). Statistical optimization of media for mycelial growth and exopolysaccharide production by Lentinus edodes and a kinetic model study of two growth morphologies. Biochemical Engineering Journal, 49(1), 104-112. https://doi.org/10.1016/j.bej.2009.12.002

12. Cui, Jian-dong, \& Jia, S. (2010). Optimization of Medium on Exopolysaccharides Production in Submerged Culture of Cordyceps militaris. 19(6), 1567-1571. https://doi.org/10.1007/s10068-010-0222-8

13. Ke, L. (2014). Optimization of ultrasonic extraction of polysaccharides from Lentinus edodes based on enzymatic treatment. Journal of Food Processing and Preservation, 1-6. https://doi.org/10.1111/jfpp.12228

14. Kwon, J. S., Lee, J. S., Shin, W. C., Lee, K. E., \& Hong, E. K. (2009). Optimization of Culture Conditions and Medium Components for the Production of Mycelial Biomass and Exo-polysaccharides with Cordyceps militaris in Liquid Culture. Biotechnology and Bioprocess Engineering, 14, 756-762. https://doi.org/10.1007/s12257-009-0024-0

15. Lung, M., \& Huang, P. (2010). Optimization of exopolysaccharide production from Armillaria mellea in submerged cultures. Applied Microbiology, 50, 198-204. https://doi.org/10.1111/j.1472-765X.2009.02777.x

16. Mahapatra, S., \& Banerjee, D. (2013). Optimization of a bioactive exopolysaccharide production from endophytic Fusarium solani 
SD5. Carbohydrate Polymers, 97, 627-634.

17. Shenbhagaraman, R., Jagadish, L. K., \& Premalatha, K. (2012). Optimization of extracellular glucan production from Pleurotus eryngii and its impact on angiogenesis. International Journal of Biological Macromolecules, 50, 957-964. https://doi.org/10.1016/j.ijbiomac.2012.02.008

18. Zárate-Chaves, C. A., Romero-Rodríguez, M. C., Niño-Arias, F. C., Robles-Camargo, J., Linares-Linares, M., Rodríguez-Bocanegra, M. X., \& Gutiérrez-Rojas, I. (2013). Optimizing a culture medium for biomass and phenolic compounds production using Ganoderma lucidum. Brazilian Journal of Microbiology, 44(1), 215-223. https://doi.org/10.1590/S1517-83822013005000032

19. Vega-Oliveros, C. ; (2016). Comparación de la producción de metabolitos secundarios bioactivos con dos fuentes de carbono en la fermentación líquida de una especie de Pleurotus y su uso potencial en un alimento de tipo funcional.

20. Nehad, E. A. and A. R. E.-S. (2010). Physiological studies on the production of exopolysaccharide by Fungi. Agriculture and Biology Journal of North AmericaNorth America, 1, 1303-1308. https://doi.org/10.5251/abjna.2010.1.6.1303.1308

21. Chegwin Angarita, C., \& Nieto R., I. (2014). Effect of non-conventional carbon sources on the production of triterpenoids in submerged cultures of Pleurotus macrofungi. J. Chil. Chem. Soc, 59, 2287-2293. https://doi.org/10.1016/0006-2952(87)90680-0

22. Tsivileva, O. M., Nikitina, V. E., \& Garibova, L. V. (2005). Effect of culture medium composition on the activity of extracellular lectins of Lentinus edodes. Prikladnaia Biokhimiia i Mikrobiologiia, 41(2), 200-203.

23. Song, C. H., Cho, K. Y., \& Nair, N. G. (1987). A Synthetic Medium for the Production of Submerged Cultures of Lentinus Edodes . Mycologia, 79(6), 866-876. https://doi.org/10.1080/00275514.1987.12025475

24. Suárez Arango, C., \& Nieto, I. J. (2013). Cultivo biotecnológico de macrohongos comestibles: Una alternativa en la obtención de nutracéuticos. Revista Iberoamericana de Micologia, 30(1), 1-8. https://doi.org/10.1016/j.riam.2012.03.011

25. Chemat, F., \& Khan, M. K. (2011). Ultrasonics Sonochemistry Applications of ultrasound in food technology: Processing , preservation and extraction. Ultrasonics - Sonochemistry, 18(4), 813-835. https://doi.org/10.1016/j.ultsonch.2010.11.023

26. Zhang, Y., Li, S., Wang, X., Zhang, L., \& Cheung, P. C. K. (2011). Advances in lentinan: Isolation, structure, chain conformation and bioactivities. Food Hydrocolloids, 25(2), 196-206. https://doi.org/10.1016/i.foodhyd.2010.02.001

27. Shcherba, V. V, \& Babitskaya, V. G. (2004). The Carbohydrates of Submerged Mycelium of Xylotrophic Basidiomycetes. 40(6), 551554.

28. Gardezi, S. M. S. ; I. H. ; S. D. A. (2003). Estimation of Sterols in Edible Fats and Oils. Pakistan Journal of Nutrition., 2(3), $178-181$.

29. Xiong, Q., Wilson, W. K., \& Pang, J. (2007). The Liebermann-Burchard reaction: Sulfonation, desaturation, and rearrangment of cholesterol in acid. Lipids, 42(1), 87-96. https://doi.org/10.1007/s11745-006-3013-5

30. Abell, L. L., Levy, B. B., Brodie, B. B., \& Kendall, F. E. (1951). Simplified method for the estimation of total cholesterol in serum and 
demonstration of its specificity. Journal of Biological Chemistry, 195(1), 357-366. https://doi.org/10.1016/S0021-9258(19)50907-

$\underline{3}$

31. Ramona Ávila Núñez, Bernarda Rivas Pérez, R. H. M. y M. C. (2012). Contenido de azúcares totales, reductores y no reductores en Agave cocui Trelease. Multiciencias, 12(2), 129-135. Retrieved from https://www.redalyc.org/pdf/904/90424216002.pdf

32. Bajaj, I. B., Lele, S. S., \& Singhal, R. S. (2009). A statistical approach to optimization of fermentative production of poly ( c-glutamic acid) from Bacillus licheniformis NCIM 2324. Bioresource Technology, 100(2), 826-832. https://doi.org/10.1016/i.biortech.2008.06.047

33. Garcia-Ochoa, F., \& Gomez, E. (2009). Bioreactor scale-up and oxygen transfer rate in microbial processes: An overview. Biotechnology Advances, 27(2), 153-176. https://doi.org/10.1016/j.biotechadv.2008.10.006

34. Márquez-Rocha, F. J., Guillén N., G. K., Sánchez V., J. E., \& Vázquez-Duhalt, R. (1999). Growth characteristics of Pleurotus ostreatus in bioreactors. Biotechnology Techniques, 13(1), 29-32. https://doi.org/10.1023/A:1008861432337

35. Ferrer-romero, J. C. (2019). Optimización del medio de cultivo para la producción de biomasa y compuestos fenólicos por Pleurotus ostreatus en fase sumergida utilizando la metodología de superficie de respuesta Optimization of medium composition for the production of Pleurotus ostrea. 1-16.

36. Nieto R., I., \& Cucaita V., E. del. (2007). Ácidos grasos, ésteres y esteroles del cuerpo fructífero del hongo Laccaria laccata. Revista Colombiana de Química, 36(3), 277-284.

37. Xiao, J. H., Chen, D. X., Liu, J. W., Liu, Z. L., Wan, W. H., Fang, N., Liang, Z. Q. (2004). Optimization of submerged culture requirements for the production of mycelial growth and exopolysaccharide by Cordyceps jiangxiensis JXPJ 0109. 1105-1116. https://doi.org/10.1111/j.1365-2672.2004.02235.x

38. Simonić, J., Stajić, M., Glamočlija, J., Vukojević, J., Duletić-Laušević, S., \& Brčeski, I. (2008). Optimization of submerged cultivation conditions for extra- and intracellular polysaccharide production by medicinal Ling Zhi or Reishi mushroom Ganoderma lucidum (W. Curt.: Fr.) P. Karst. (Aphyllophoromycetideae). International Journal of Medicinal Mushrooms, 10(4), 351-360. https://doi.org/10.1615/IntJMedMushr.v10.i4.80

39. Hsieh, C., Tseng, M. H., \& Liu, C. J. (2006). Production of polysaccharides from Ganoderma lucidum (CCRC 36041) under limitations of nutrients. Enzyme and Microbial Technology, 38(1-2), 109-117. https://doi.org/10.1016/j.enzmictec.2005.05.004 
Figures
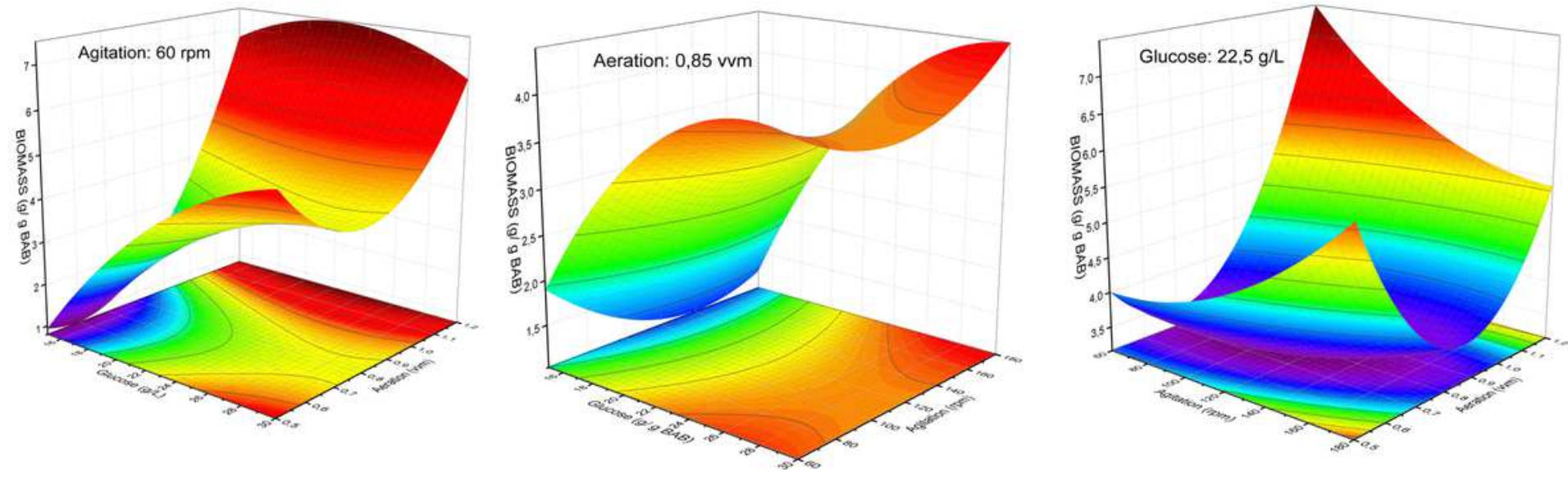

Figure 1

Effect of variables on biomass production
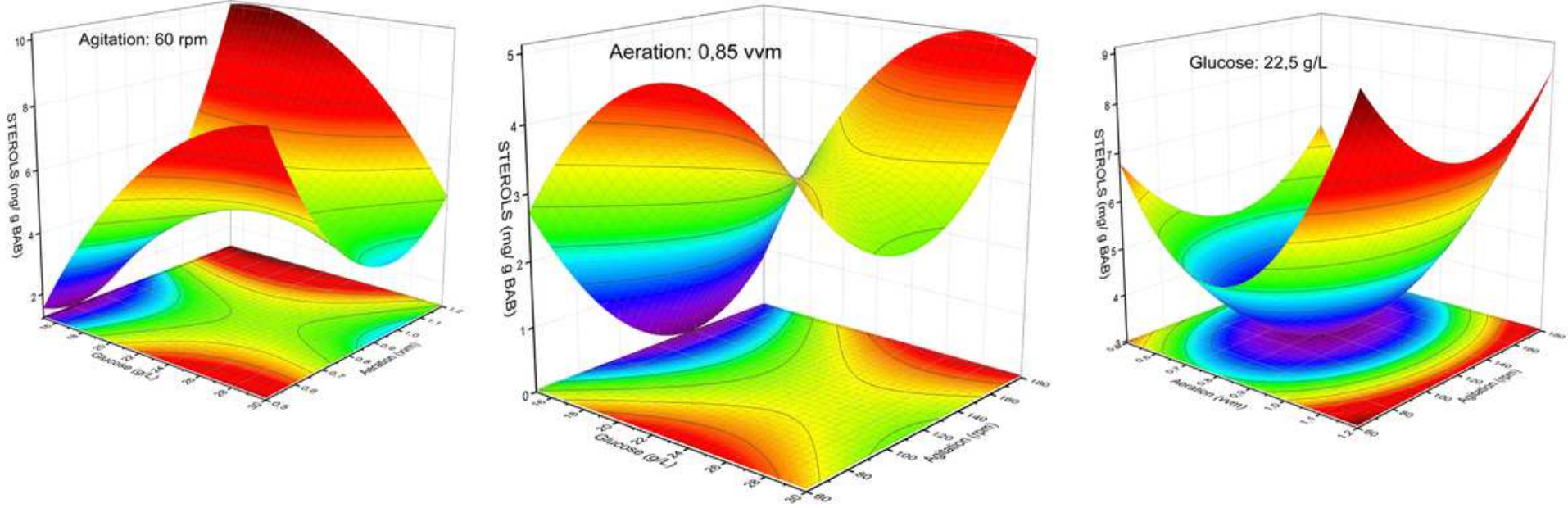

Figure 2

Effect of variables on sterols production
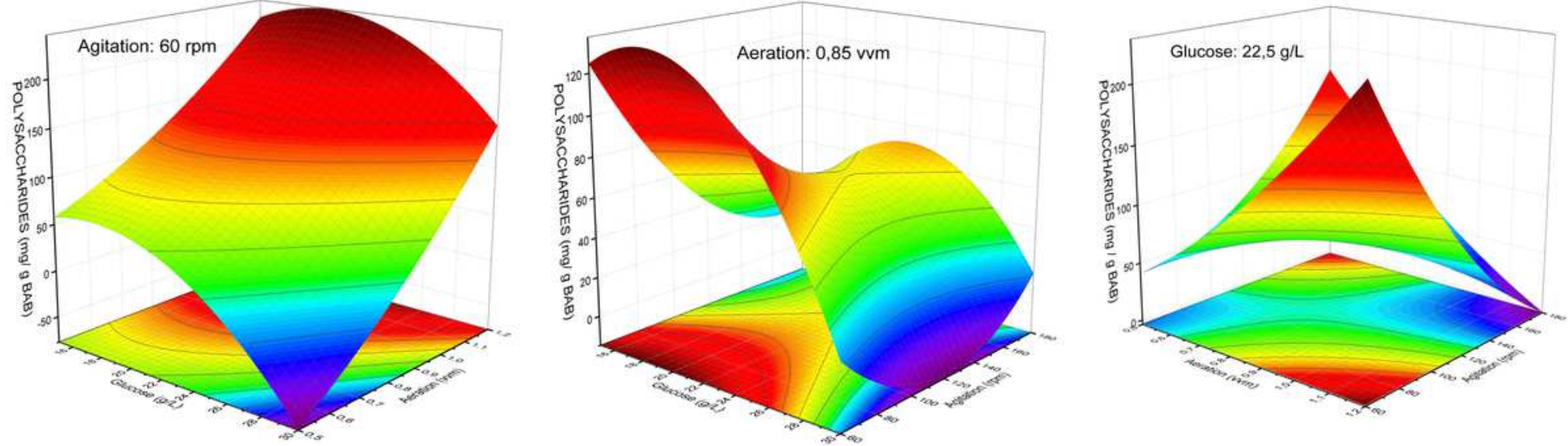

Figure 3 
Effect of variables on polysaccharides production 